\title{
Characteristics of Nanoparticles in Drinking Water Treatment using Biological Activated Carbon
}

\author{
Reni Desmiarti ${ }^{1, *}$, Yoji Morishita ${ }^{2}$, Tomonari Fujisawa ${ }^{2}$, Yasushi Ishiguro ${ }^{3}$, Toshiro Yamada ${ }^{2}$ and Fusheng Li $^{3}$ \\ ${ }^{1}$ Chemical Engineering Department, Universitas Bung Hatta, 25147, Padang, Indonesia \\ ${ }^{2}$ Civil Engineering Department, Gifu University, 501-1193, Gifu, Japan \\ ${ }^{3}$ River Basin Research Center, Gifu University, 501-1193, Gifu, Japan
}

\begin{abstract}
Characteristics of nanoparticles in drinking water treatment were performed using five types of biological activated carbon (BAC) columns (BAC1-BAC5) in continuous flow experiments. The BAC was created by covering granular activated carbon (GAC) with attached microorganisms from water samples taken from the Nagara River in Japan. The total running time was about $2000 \mathrm{~h}$. The characteristics of the nanoparticles were investigated based on size distribution and volume distribution measured by Zetasizer Nano. Total dissolved organic carbon (DOC) and ultraviolet absorbance at $260 \mathrm{~nm}$ (UV260) were also studied. The important results in this study were that the detached nanoparticles in the effluent were within the size distribution ranges of $0.26 \sim 5.62 \mathrm{~nm}, 0.62 \sim 3.62 \mathrm{~nm}, 0.62 \sim 3.12 \mathrm{~nm}, 0.62 \sim 4.19 \mathrm{~nm}$, and $0.62 \sim 6.50$ for BAC 1, 2, 3, 4 and 5, respectively. The profile of peak size and peak number along the bed depth of the BAC columns was evaluated for better understanding the characteristics of the nanoparticles. This result is very important for improving drinking water treatment using granular activated carbon to remove microorganisms.
\end{abstract}

\section{Introduction}

In Japan, water resource development used for domestic and industrial water accounts for $71 \%$ of water intake from rivers. The Nagara River, one of three rivers used as water resources in Japan, is used to satisfy the population demand for water in Aichi Prefecture, a region located in the center of Japan [1]. The water is flowed through a treatment plant and then distributed to communities in Aichi Prefecture. One of the technologies used in the drinking water treatment plant is adsorption by activated carbon.

Activated carbon technology is one of the most mature and effective processes in drinking water treatment. Application of activated carbon was demonstrated to remove organic micropollutants such as pharmaceuticals, phenols, Trihalomethane (THMs) and pesticides. The activated carbon was also used to reduce odor and colour in drinking water treatment plant $[2,3]$. Activated carbons have varied surface characteristics and pore size distributions. These characteristics of activated carbon play an important role in the adsorption of contaminants in water $[4,5]$. Biological activated carbon (BAC) filtration has been investigated as a pre-treatment for reducing organic fouling, thus allowing a higher sustainable flux for microfiltration $[5,6]$.

Although there have been numerous experimental studies on water adsorption by activated carbons, little is known about the removal of nanoparticles using this method. Exposure to nanoparticles through the ingestion of drinking water may pose a potential direct human health threat or an indirect risk, including DNA damage $[7,8]$. The characteristics of normal organic contents (NOM) as DOC and UV260 have been studied $[9,10,11,12]$. The purpose of the present study was to investigate the characteristics of nanoparticles in water taken from the Nagara River using five types of biological activated carbon (BAC) columns (BAC1BAC5) in continuous flow experiments. The characteristics of the nanoparticles were investigated based on size distribution and volume distribution measured by Zetasizer Nano. Zeta potential was also measured to predict the stability of colloidal nanoparticles in effluent. Furthermore, DOC and ultraviolet absorbance at $260 \mathrm{~nm}$ (UV260) were also studied to quantify the content of natural organic matter in water.

\section{Materials and methods}

\subsection{Materials}

Water samples were collected from the right side of the Nagara River, located near Nagara Bridge, Gifu Prefecture. The sampled water sample was filtered on site using a sieve of $38 \mu \mathrm{m}$ pore size to remove relatively large organic matters such as fallen leaves and fallen branches floating in the river water. The sampling was conducted once a week.

Corresponding author: renidesmiarti@gmail.com 


\subsection{Preparation of activated carbons}

In this study, five activated carbons with different pore distributions were pulverized and used for the experiment. Before using the activated carbon for the experiment, the surface area was cleaned by washing with water and boiled for about 1 hour to remove impurities in the activated carbon pores and then dried at $105{ }^{\circ} \mathrm{C}$ to $115^{\circ} \mathrm{C}$ (FO810, Yamato Scientific Co., Ltd.). In this study, five types of activated carbon were used; the characteristics of each type are presented in Table 1.

Table 1. Activated carbon pore volume and pore size distribution

\begin{tabular}{|l|c|c|}
\hline Name & $\begin{array}{c}\text { Pore volume } \\
\left(\mathrm{cm}^{3} / \mathrm{g}\right)\end{array}$ & $\begin{array}{c}\text { Pore size distribution } \\
\left(\mathrm{m}^{2} / \mathrm{g}\right)\end{array}$ \\
\hline BAC 1 & 0.532 & 1192 \\
\hline BAC 2 & 0.356 & 1025 \\
\hline BAC 3 & 0.483 & 1088 \\
\hline BAC 4 & 0.350 & 1200 \\
\hline BAC 5 & 0.518 & 1029 \\
\hline
\end{tabular}

\subsection{Continuous flow experiment}

The column used for water the flow experiments was composed of a vinyl chloride tube with a diameter of $2.54 \mathrm{~cm}$. The tube was filled with activated carbon to a depth of $15 \mathrm{~cm}$. The flow rate of the sample water was controlled by adjusting the pump so that the residence time in each column was constant (20 min). A schematic figure, similar to that given in Li et al. [13], the granular activated carbon column apparatus is shown in Figure 1.

The effluent was collected twice every week and promptly filtered through a $0.2 \mu \mathrm{m}$ membrane filter (manufactured by ADVANTEC Corporation, Cellulose Acetate material) for the purpose of analysis.

\subsection{Analysis}

The effluent from each column was sampled. The sampled water was filtered using a $0.2 \mu \mathrm{m}$ membrane filter (manufactured by ADVANTEC Corporation, Cellulose Acetate material) before being subjected to analysis. Dissolved organic carbon (DOC) was analysed using a total organic carbon (TOC) analyser (TOC-V, manufactured by Shimadzu). A UV-visible spectrophotometer (U-3210, Hitachi Co., Ltd.) was used for measurement of the UV-absorbance at $260 \mathrm{~nm}$ (UV260). The index of UV260 is accomplished of reflecting the present of humic molecules in water and the specific ultraviolet absorption (SUVA), a calculated parameter of UV260 divided by DOC, can thus be used as a humic content indicator.

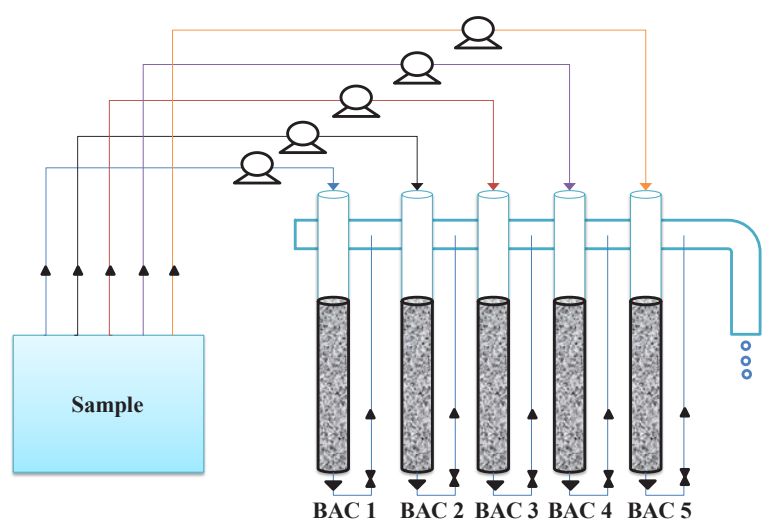

Fig. 1. Schematic figure of granular activated carbon column apparatus.

Three-dimensional fluorescence excitation-emission matrix (RF-EEM) spectroscopy was used to differentiate different types and origin of dissolved organic carbon (DOC) in the effluent. EEM was measured using an RF5300 PC spectrofluorometer (manufactured by Shimadzu Corporation) using a xenon lamp as light source. For measurement conditions, the slit width was $5 \mathrm{~nm}$ for both excitation wavelength and fluorescence wavelength; the measurement range was 220 to $550 \mathrm{~nm}$; the data sampling interval was $5 \mathrm{~nm}$; the sensitivity setting was high; and the response time was $0.02 \mathrm{sec}$. The fluorescence intensity of the obtained data was calculated by correcting the fluorescence intensity at excitation wavelength $350 \mathrm{~nm} /$ fluorescence wavelength $450 \mathrm{~nm}$ of the $10 \mathrm{ppb}$ quinine sulfate solution at room temperature to the relative fluorescence intensity as 1 QSU (Quinine Sulfate Unit). Furthermore, nanoparticle size distribution and zeta potential analysis were carried out using a zeta potential meter (Zetasizer Nano, manufactured by Malvern).

\section{Results and discussions}

\subsection{UV absorbance at $260 \mathrm{~nm}$ wavelength}

The behavior of natural organic matter and nanoparticles in each column over elapsed time from the continuous flow experiment is shown in Figure 2. In each column, the removal rate exceeded $80 \%$ at the initial stage of the experiment. However, after over 500 hours, the removal rates of columns BAC 2 and BAC 3, which had relatively large pore volumes, gradually decreased. The performance of columns BAC 1 and BAC 5 remained stable throughout the experiment with an average removal rate of $80 \%$.

This indicates that for all organic components contained in the Nagara river water, UV260 components were excellently adsorbed, while some constituents not detected by UV260 were less favourably adsorbed. This is similar to the result found by Li et al. [13]. 


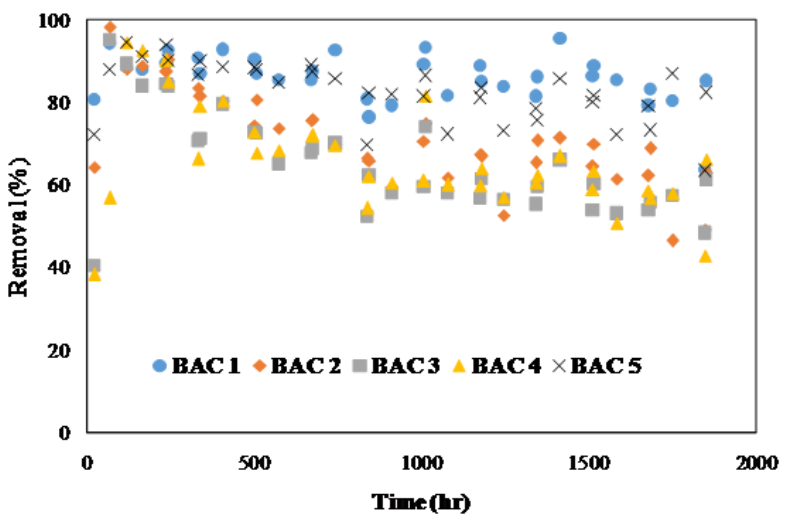

Fig. 2. Removal of organic matter analysis by UV260 absorbance.

\subsection{Dissolved organic carbon (DOC)}

The dissolved organic matter measured as DOC removal during the experiment is shown in Figure 3.

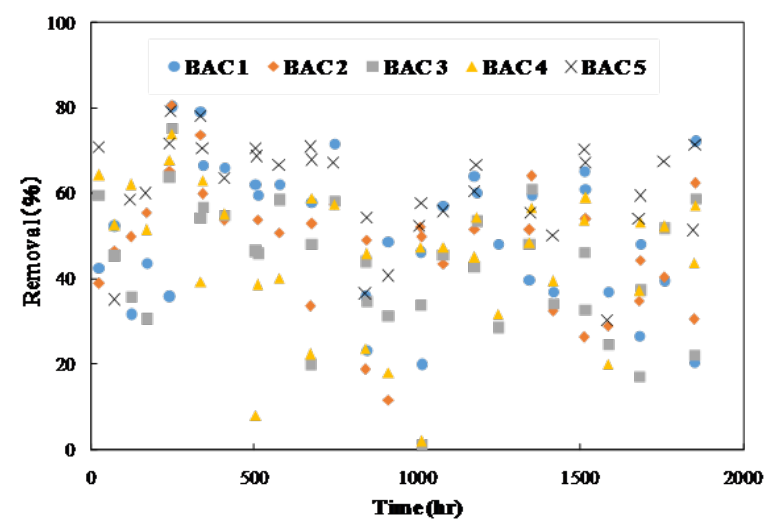

Fig. 3. Removal of DOC removal during continuous flow experiment.

Looking at the changes in DOC removal rate over time for each column, the results are varied and it is difficult to confirm a clear trend, even if the pore sizes and pore size distributions of the granular activated carbons packed in these columns were different, as shown in Table 1. It is thus reasonable to infer that the organic contents of the effluent consisted of those not absorbable by activated carbon. The presence of non-absorbable components was also defined in Nagara river water [13].

\subsection{Fluorescence properties}

A three-dimensional excitation emission matrix fluorescence spectroscopy (3DEEM) can provide significant information on the chemical nature and source of dissolved organic carbon (DOC) [14, 15]. Figures 4-9 present the 3DEEM characteristics for the DOM fractions for raw water and effluent in each BAC column. Peak 1 (Ex/Em, Ex: 320-350 nm; Em: 435-450 $\mathrm{nm}$ ) and peak 2 (Ex/Em, Ex: 250-260 nm; Em: 430-460 $\mathrm{nm})$ shown in each figure represent humic-like substances, while peak 3 (Ex/Em, Ex: 260-270 nm; Em: $340-350 \mathrm{~nm}$ ) represents protein-like substances.

From Figure 5-9 it can be seen that after 2 weeks of experiment only protein-like substances were observed in every BAC column, suggesting the formation of biofilm. The humic-like substance peak did not appear in all columns, indicating that adsorption in the BAC column had occurred. However, this peak was not observed after 4 weeks of continuous flow experiment. Also, there were no differences in the maximum Ex/Em wavelengths of the protein-like fractions, except for column BAC 5. Coble et al [15] has informed that DOM fractions of the blue shift of the Ex wavelength reflect a quite small molecular weight composition (lower intensity), while a red shift reflects a quite larger molecular weight composition (higher intensity). Peak 3 of column BAC 5 displayed the highest fluorescence intensity at 2 weeks, but it could hardly be observed after 4 weeks.

\subsection{Size distribution and zeta potential}

The nanoparticle size distribution was measured of which the result is shown in Figures 10 and 11. After 2 weeks of experiment, particles of 0.35-10 nm represented the majority of nanoparticle occupied volume.

However, after 4 weeks of experiment, there was a shift in size distribution. The size of nanoparticles found in columns BAC 2 and BAC 3 was increased, as larger sizes of nanoparticles occupying the effluent were detected. This indicates that after 4 weeks, columns BAC 2 and BAC 3 had a limitation in adsorbing the organic matter contained in the river water. For the other columns, the size distribution remained the same. The detached nanoparticles in the effluent were within the size distribution number ranges of $0.26-5.62 \mathrm{~nm}, 0.62$ $3.62 \mathrm{~nm}, 0.62-3.12 \mathrm{~nm}, 0.62-4.19 \mathrm{~nm}$, and $0.62-6.50$ for BAC 1, 2, 3, 4 and 5, respectively. 

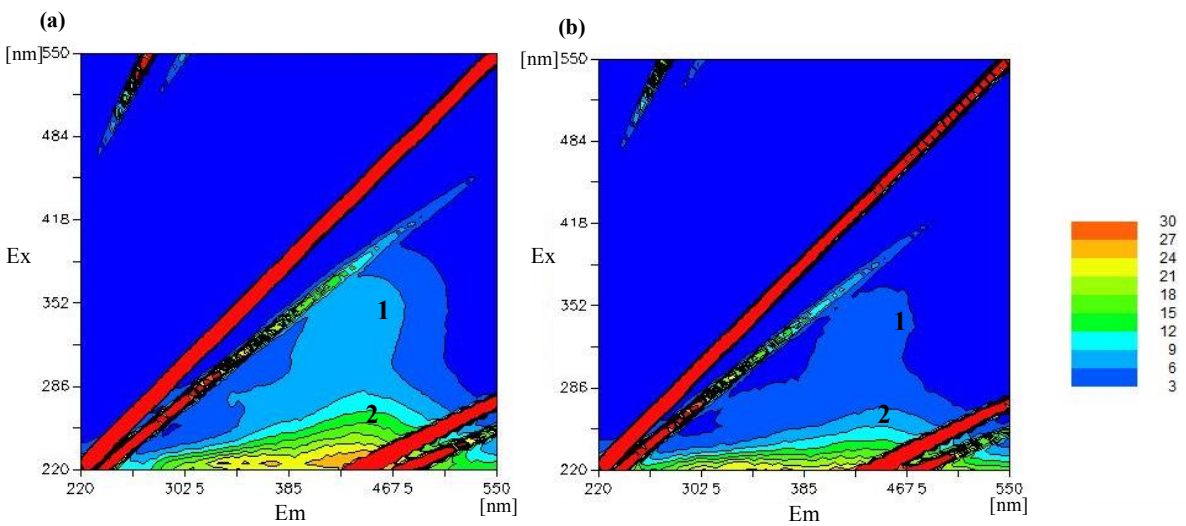

Fig. 4. The 3DEEM plots of raw water (a) at 2 weeks (b) at 4 weeks
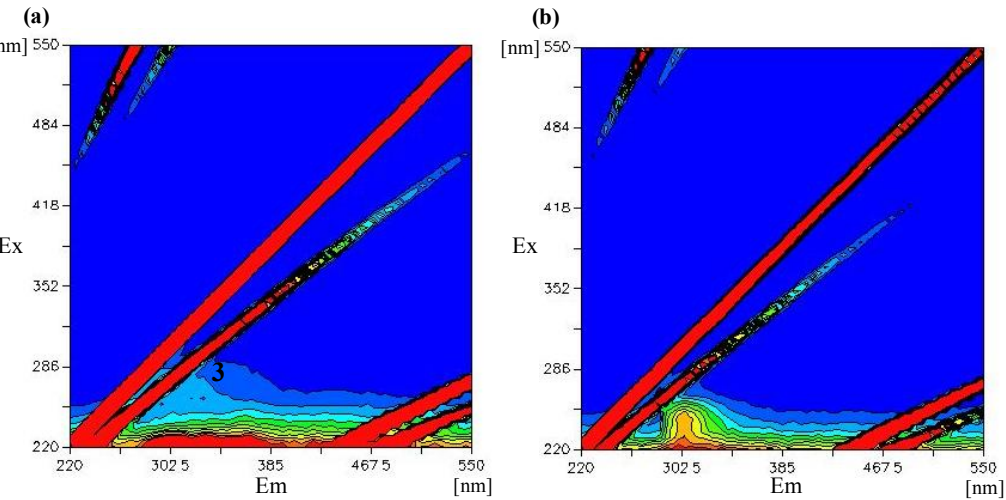

Fig. 5. The 3DEEM plots of BAC 1 (a) at 2 weeks (b) at 4 weeks
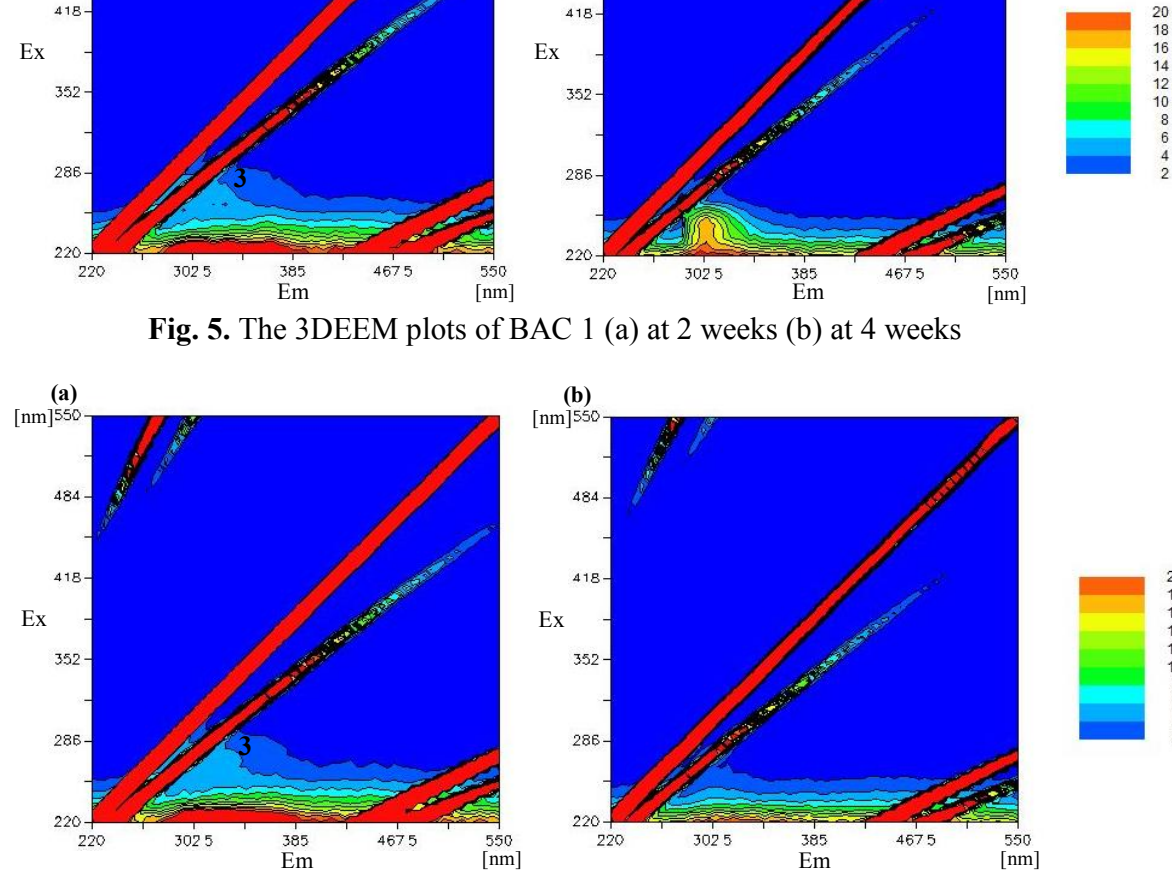

Fig. 6. The 3DEEM plots of BAC 2 (a) at 2 weeks (b) at 4 weeks
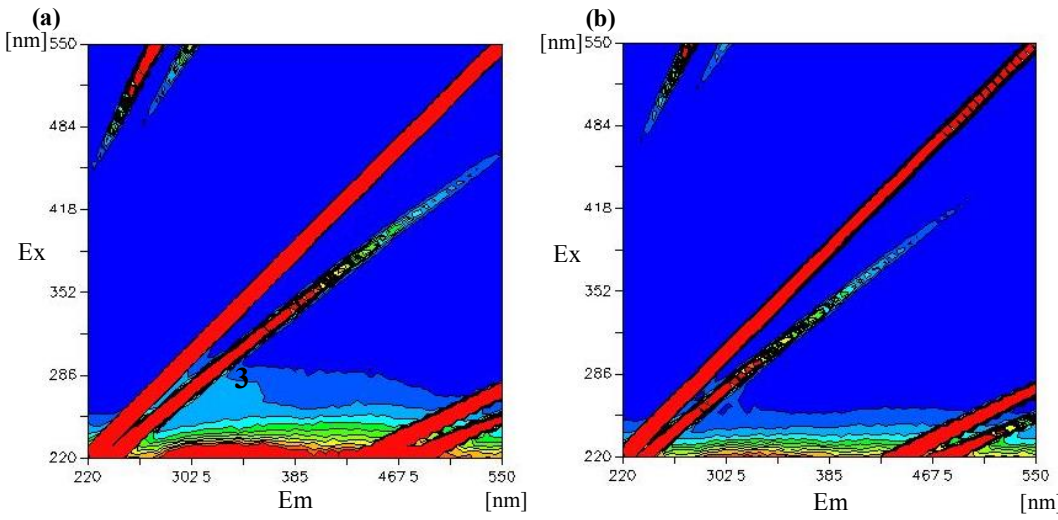

Fig. 7. The 3DEEM plots of BAC 3 (a) at 2 weeks (b) at 4 weeks 

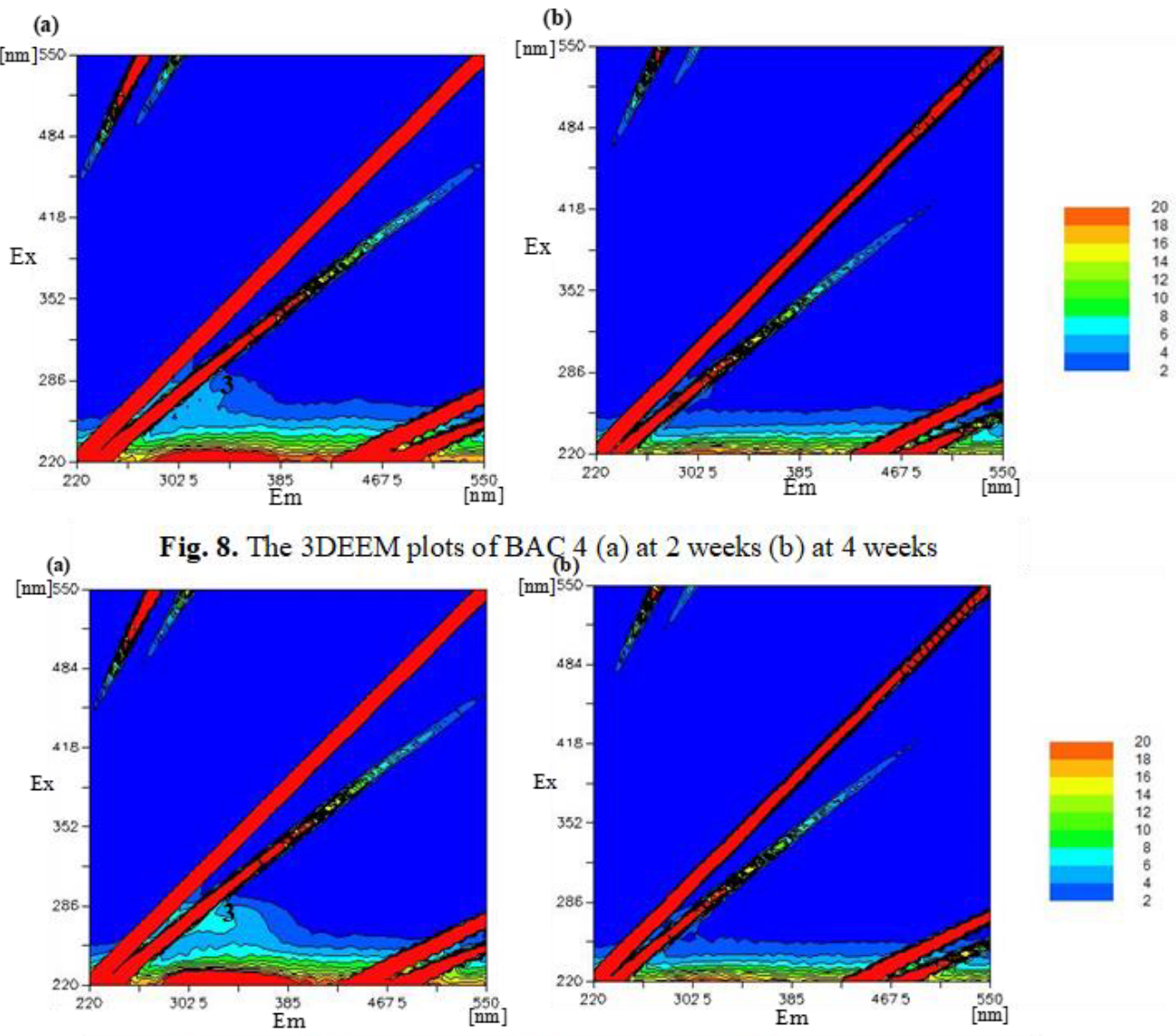

Fig. 9. The 3DEEM plots of BAC 5 (a) at 2 weeks (b) at 4 weeks

(a)

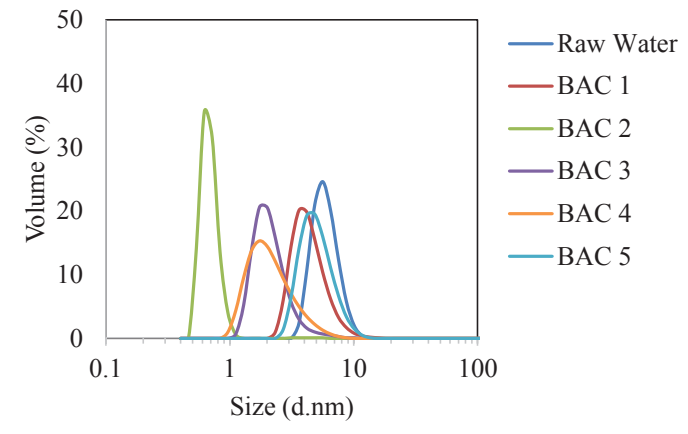

(b)

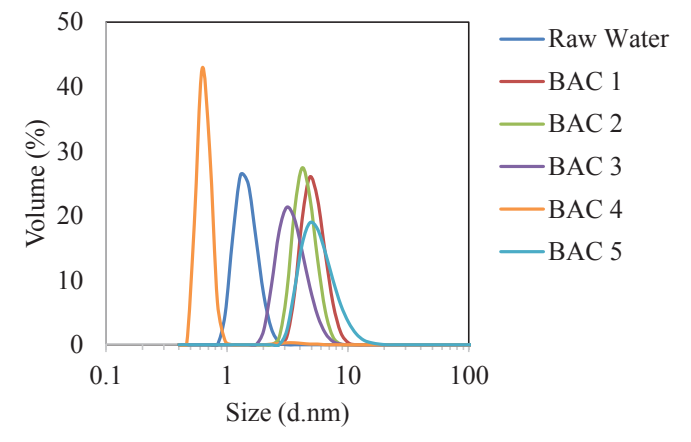

Fig. 10. Volume size distribution of nanoparticles (a) at 2 weeks (b) at 4 weeks (a)

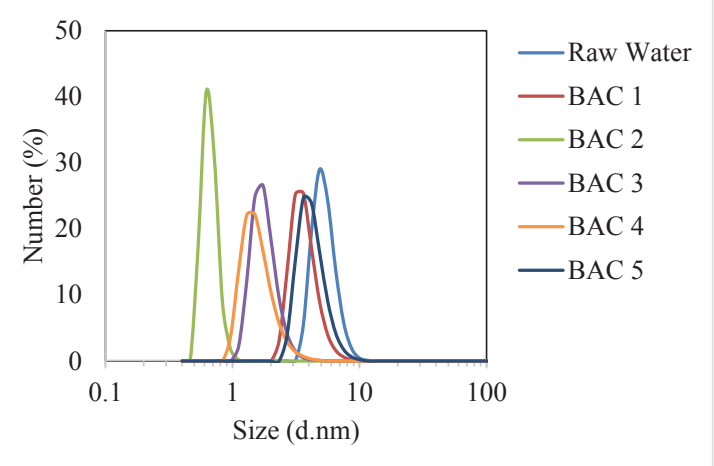

(b)

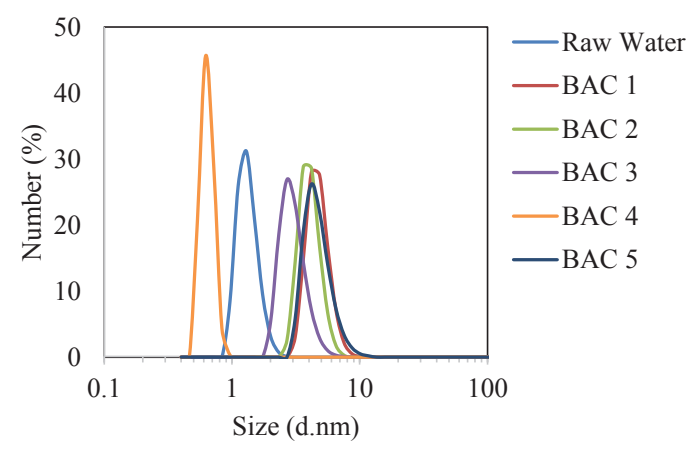

Fig. 11. Number size distribution of nanoparticles (a) at 2 weeks (b) at 4 weeks 
Table 2 summarizes the zeta potential and electrophoretic mobility values obtained for the different continuous flow columns of biological activated carbon. The table also includes the measured conductivity values for these samples. In the results summarized above, the measured mobility values after 2 weeks of experiment were consistent for every BAC column. However, after 4 weeks of investigation, the mobility values became less negative, i.e. the magnitude of mobility decreased. This indicates that the increase of nanoparticles present in the effluent resulted in obscuration of light transmission. Furthermore, the measured zeta potential values were decreased after 4 weeks of experiment. This indicates that the stability of the colloidal nanoparticles was reduced and adsorption by biological activated carbon had occurred.

Table 2. Zeta potential and electrophoretic mobility results for various biological activated carbon (BAC)

\begin{tabular}{|c|c|c|c|c|}
\hline $\begin{array}{c}\text { Time } \\
\text { (weeks) }\end{array}$ & $\begin{array}{c}\text { AC } \\
\text { column }\end{array}$ & $\begin{array}{c}\text { Zeta } \\
\text { potential } \\
(\mathrm{mV})\end{array}$ & $\begin{array}{c}\text { Electrophoretic } \\
\text { mobility } \\
\left(\mathrm{m}^{2} \mathrm{Vs}^{-1} \times 10^{-8}\right)\end{array}$ & $\begin{array}{c}\text { Conductivity } \\
\left(\mathrm{mS} \mathrm{cm}^{-1}\right)\end{array}$ \\
\hline 2 & BAC 1 & -22.9 & -1.7980 & 0.0818 \\
\cline { 2 - 5 } & BAC 2 & -21.9 & -1.7170 & 0.0817 \\
\cline { 2 - 5 } & BAC 3 & -24.1 & -1.8870 & 0.0851 \\
\cline { 2 - 5 } & BAC 4 & -10.3 & -0.8048 & 0.0857 \\
\cline { 2 - 5 } & BAC 5 & -11.9 & -0.9296 & 0.0817 \\
\hline 4 & BAC 1 & -4.68 & -0.3669 & 0.0857 \\
\cline { 2 - 5 } & BAC 2 & -3.18 & -0.2492 & 0.0844 \\
\cline { 2 - 5 } & BAC 3 & -6.05 & -0.4746 & 0.0802 \\
\cline { 2 - 5 } & BAC 4 & -2.64 & -0.2071 & 0.0842 \\
\cline { 2 - 5 } & BAC 5 & -7.77 & -0.6093 & 0.0850 \\
\hline
\end{tabular}

\section{Conclusions}

Dissolved organic matter in Nagara River was characterized into two major components: humic-like substances and protein-like substances. After 2 weeks of experiment only protein-like substances were observed in every BAC column. However, the humic-like substance peak did not appear in all columns, indicating that adsorption by BAC had occurred. Organic matter removal rates of $80 \%$ were obtained in each BAC column as indicated by UV260 absorbance and DOC measurement. After 4 weeks of continuous flow experiment, the measured zeta potential values were decreased, indicating that the stability of the colloidal nanoparticles was reduced and adsorption by biological activated carbon had occurred. The detached nanoparticles in the effluent were within the size distribution ranges of $0.26-5.62 \mathrm{~nm}, 0.62-3.62 \mathrm{~nm}, 0.62-$ $3.12 \mathrm{~nm}, 0.62-4.19 \mathrm{~nm}$, and 0.62-6.50 for BAC 1, 2, 3, 4 and 5 , respectively.
This study was supported the JASSO Follow-up Research Fellowship for the fiscal year 2016 from Gifu University, Japan. This work was also supported by Ministry of Research, Technology and Higher Education, Republic of Indonesia (RISTEK DIKTI) in accordance with the Contract of Research Number: 001/KONTRAK-PENELITIAN/K10/ KM/2017 dated April $10^{\text {th }}, 2017$

\section{References}

1. Kiso River Lower Reaches Works Office, Chubu Regional Construction Bureau, Ministry of Land, Infrastructure and Transport, (2004)

2. E. Worch, Adsorption technology in water treatment (Walter de Gruyter GmbH \& Co. KG, Berlin/Boston, 2009)

3. R. Desmiarti \& F. Li, ITB J. Eng. Sci., 43, 2, 153160 (2011).

4. S. Ismadji, S.K Bhatia, Carbon 39, 1237-1250 (2001)

5. O. Gibert, B. Lefevre, M. Fernandez, X. Bernard, M. Paraira, M. Calderer, X. Martinez, Water Research, 47, 1101-1110 (2013)

6. J. Niu, I. Kasuga, F. Kurisu, H. Furumai, T. Shigeedaa, Water Research, 47, 7053-7065 (2013

7. V. Sharma, P Singh, A.K. Pandey, A. Dhawan, Mutat Res 745, 1-2, 84-91 (2012).

8. Antizar-Ladislao, B., Lopez-Real, J. \& Beck, A.J., Chemosphere, 64, 5, 839-847 (2006).

9. H. Gui, F. Li, Y. Wei, T. Yamada, R. Desmiarti, J Eng. Technol. Sci. 48, 5, 631-644 (2016)

10. S.A Baghoth, S.K. Sharma, G.A. Almi, Water Research, 45, 797-809 (2011)

11. Sheng, G.P. \& Han, Q.Y., Water Research, 40, 6, 1233-1239 (2006).

12. W. Chen, P. L. Westerhoff, J. A. Leenheer, K. Booksh, Environ. Sci. Tech. 37, 24, 5701-5710 (2003)

13. F. Li, A. Yuasa, H. Tanaka, Y. Katamine, Adsorption, 14, 389-398 (2008).

14. A. Baker, Environ. Sci. Tech. 35, 5, 948-953 (2001)

15. P.G. Coble, Mar. Chem. 51, 4, 325-346 (1996) 